DOI: $10.17805 /$ trudy.2018.3.10

\title{
ВИРТУАЛЬНЫЙ БРЕНД: ПОДХОДЫ К ОПРЕДЕЛЕНИЮ
}

\author{
М. А. Симакина \\ Московский гуманитарный университет
}

Аннотация: В статье рассматриваются основные характеристики виртуальности и виртуальной реальности.

Текст доклада автора на Всероссийской научной конференции «Культура между Логосом и Мифом: к проблеме бессознательного (к 80-летию А. Э. Воскобойникова)», которая прошла в Московском гуманитарном университете 26-27 октября 2017 года.

Ключевые слова: бренд; виртуальный; виртуальная реальность; информационное общество; виртуальный бренд

\section{VIRTUAL BRAND: APPROACHES TO THE DEFINITION}

\author{
M. A. Simakina \\ Moscow University for the Humanities
}

Аннотация: The article considers the main characteristics of virtuality and virtual reality.

The text of the author's speech at the All-Russian Scientific Conference "Culture between Logos and Myth: on the Issue of the Unconscious (dedicated to the 80th anniversary of A. E. Voskoboynikov)", which was held at Moscow University for the Humanities on 26-27 October 2017.

Ключевые слова: brand; virtual; virtual reality; information society; virtual brand

Исследователи теории виртуального возводят этимологию термина к римскому стоицизму и схоластической философии. Они отмечают, что термин virtus встречается в работах Марка Туллия Цицерона в значении «добродетель».

Шотландский теолог, Блаженный Иоанн Дунс Скот настаивал на том, что понятие вещи содержит в себе эмпирические атрибуты не формально, но виртуально, т. е. виртуальность - это информационный эквивалент вещей.

Также, термин «виртуальный» употреблялся Василием Великим и Фомой Аквинским в значении потенции, сущности и причины. Например, в 
Научные труды Московского гуманитарного университета 2018 № 3

«Беседе на шестиднев» Василий Великий представлял виртуальность как некую сущность материальных объектов, заключенную в потенции и раскрывающуюся в процессе воплощения в действительности. Следовательно, основная функция виртуальности в средневековой философии состояла в дополнении ведущей модели реальности, теологической. В работах Николая Кузанского «виртуальными» назывались те события, теоретические аналоги которых отсутствовали в теологической модели реальности. Виртуальная реальность понималась антиреалистично, она не принадлежала объективной реальности, не могла быть познана эмпирически (Леушкин, 2014). С таких позиций можно трактовать виртуальность как выход за пределы обыденности, изменение своего сознания, мгновенная актуализация своих латентных возможностей, инаковый взгляд на мир.

Активно исследовавшийся в Средние века термин оказался совершенно неинтересен философам Нового времени. Дальнейшее свое развитие термин virtus получил уже в XIX веке. Кант, Лейбниц, Фейербах сохраняют стандартное значение термина как добродетели, силы, потенции. Анри Бергсон употребляет термин «виртуальное» как синоним возможного, потенциального. Антонен Арто применял термин «виртуальная реальность» применительно к искусству театра задолго до Джайрона Ланье, которому принадлежит заслуга в популяризации этого словосочетания в конце 80-х годов XX века.

В Новейшее время, под влиянием развития информационных технологий, термин приобрел новое значение. Современный философский дискурс представляет виртуальность как несомненно познаваемую ввиду того, что она частично наличествует в реальности в виде объектов с неполным существованием. Их неполнота выражена в отсутствии таких физических характеристик, как метричность (протяженность, длительность), наглядность, актуальность. Зачастую виртуальный объект обнаруживается в результате взаимодействия с реальным объектом и изменением структуры последнего (там же). Сходство и сродство понятий «виртуальность» и «виртуальная реальность» приводит к пониманию виртуальности как некоторого состояния, при котором субъект теряет различие между реальным и сконструированным (виртуальным) миром, т. е. виртуальность становится характеристикой сознания и восприятия субъекта (Рузавин, 2010). Для Бодрийяра виртуальна знаковая реальность, гиперреальность, в которой «процесс симуляции зашел так далеко, что утратилось само различие фантазии и реальности», фактически это пространство симулякров. Это общепринятая постмодернистская трактовка понятия «виртуальная реальность», где означающее исчезает, а его место занимает фантомный объект, не отражающий реальность, но вытесняющий и заменяющий ее дублем. 
Непосредственно с термином «виртуальный» связан термин «виртуальная реальность». Исследователи полагают (Хэмит, 1995), что впервые в научный оборот термин «виртуальная реальность» был введен в конце 1970-х годов в Массачусетском Технологическом Институте, чтобы выразить присутствие человека к создаваемом компьютером пространстве. Еще одним автором термина называют Джайрона Ланье, который понимал под «виртуальной реальностью» трехмерный мир (киберпространство), созданный компьютером и воспринимаемый человеком с помощью специальных устройств. Само понятие «киберпространство» ввел в 1984 г. Уильям Гибсон в научно-фантастическом романе «Neuromancer» и определил его как «согласованную галлюцинация, которую каждый день испытывают миллиарды обычных операторов во всем мире... Это графическое представление банков данных, хранящееся в общемировой сети компьютеров, подключенных к мозгу каждого человека» (Гибсон, Электр. ресурс).

Виртуальная реальность в техническом смысле стала артефактом современной культуры и, более того, она смогла соединить достаточно противоречивые понятия виртуальности и реальности (Кирик, 2007; Рузавин, 2010). Благодаря этому у понятия «виртуальный» появились новые смысловые оттенки: нематериальность, нетелесность, наличие носителя, субъективность восприятия. Виртуальное стало пониматься как явление, связанное с деятельностью сознания человека.

Обращаясь к исследуемому нами термину «бренд», мы можем заметить, что некоторая виртуальность присутствует в нем всегда. Известный американский рекламист Дэвид Огилви определял бренд как неосязаемую сумму свойств продукта. Многие современные авторы определяют бренд как совокупность нескольких аспектов, которые в разное время возникали в литературе по брендингу:

-Уникальное эмоционально-позитивное образ-представление, обусловленное особенностями продукта и его обрамления, ставшее широко известным общественности и принятое определенными группами людей аудиториями бренда;

- Обещание потребителям желаемых потребительских свойств и уровня качества;

- Гарантия качественного удовлетворения запросов потребителя, получения конкретных выгод;

• Повышенный субъективный уровень ценности продукта для потребителя и его удовлетворенности, формируемый через позитивные ассоциации, побуждающие к потреблению данного продукта и напоминающие о нем;

-Инструмент быстрого и уверенного потребительского выбора и принятия решения о покупке; 
Научные труды Московского гуманитарного университета 2018 № 3

- Важнейший фактор конкурентных преимуществ и доходов фирмы, основание для назначения более высокой цены, часто сам по себе - наиболее ценный актив экономики фирмы (Панкрухин, 2001).

Не сложно заметить, что бренд во всех этих характеристиках выступает именно как фантомный объект, заменяющий собой реальный продукт и способствующий новому восприятию окружающей реальности. Однако, виртуальный по своей сути бренд, должен иметь некоторые вполне реальные характеристики, чтобы проявляться во взаимодействии с потребителем. Сознание человека должно на что-то опираться, чтобы воспринять бренд и выразить свое к нему отношение. Маркетологи для фиксации структуры бренда используют модель «колесо бренда», разработанную компанией «Bates Worldwide». Ее составляющие это:

1. Атрибуты - то, что представляет собой бренд, его физические и функциональные характеристики;

2. Выгоды, преимущества - то, что бренд дает потребителю, какой физический результат получает потребитель от пользования брендом;

3. Ценности - то, что чувствует потребитель, пользуясь брендом, и какое отношение бренд вызывает со стороны общества (эмоциональные результаты пользования им);

4. Индивидуальность - то, что предполагает наделение товара индивидуальными качествами, которые обеспечивают эмоциональную связь с целевыми потребителями и делают его узнаваемым и легко идентифицируемым;

5. Суть - включает все атрибуты бренда, комплексно воспринимаемые потребителями, формируя уникальную суть, которую невозможно подделать или скопировать.

В условиях информационного общества, когда товаром и объектом экономики окончательно становится информация, у бренда появляются новые виртуальные качества. Рассмотрим сначала идею «информационного общества», в котором происходит дополнительная виртуализация бренда.

При всём многообразии определений термина «информационное общество» его отличительными чертами обычно называют: существенное увеличение в валовом внутреннем продукте доли отраслей экономики, связанных с производством знаний, с созданием и внедрением наукоемких, в том числе информационных, технологий, других продуктов интеллектуальной деятельности, с оказанием услуг в области информатизации, связи, а также в области поиска, передачи, получения и распространения информации (информационных услуг); ускорение научно-технического прогресса и превращение научных знаний в реальный фактор производства, повышения качества жизни человека и общества; участие значительной части трудоспособного населения в производственной деятельности, связанной с 
созданием и использованием информационных технологий, информации и знаний; существенное расширение возможностей граждан по поиску, получению, передаче, производству и распространению информации и знаний; глобализация экономической, политической и духовной сфер жизни общества; создание глобального информационного пространства, обеспечивающего эффективное информационное взаимодействие людей, их доступ к мировым информационным ресурсам и удовлетворение их потребностей в информационных продуктах и услугах (Симакина, 2012: 70).

Процесс вхождения современного человека в информационное общество называют дигитализацией, информатизацией или даже киберсоциализацией. Российские исследователи разработали модель киберсоциализации человека на основе известной теории потребностей А. Маслоу (см. таб. 1).

Таблица 1. Киберсоциализация населения (человека)

\begin{tabular}{|c|c|}
\hline Тип потребности (по А. Маслоу) & $\begin{array}{c}\text { Способ реализации } \\
\text { в киберпространстве }\end{array}$ \\
\hline Духовные & $\begin{array}{l}\text { Многообразие возможностей презенто- } \\
\text { вать себя в киберпространстве и развитие } \\
\text { собственной личности. }\end{array}$ \\
\hline Престижные & $\begin{array}{l}\text { Опубликование собственного творчества } \\
\text { в Сети; обмен уважениями по поводу твор- } \\
\text { чества; одобрение, признание, оценка. }\end{array}$ \\
\hline Социальные & $\begin{array}{l}\text { Социальные сети и игровые сообщества } \\
\text { как принадлежность к определенным со- } \\
\text { циальным группам, установление новых } \\
\text { социальных связей, общение, организация } \\
\text { совместной деятельности. }\end{array}$ \\
\hline Экзистенциальные & $\begin{array}{l}\text { Анонимность коммуникации удовлетво- } \\
\text { ряет потребность в безопасности; рас- } \\
\text { пространение компьютерных технологий } \\
\text { приводит к комфорту и установлению по- } \\
\text { стоянства условий жизнедеятельности. }\end{array}$ \\
\hline Физиологические & $\begin{array}{l}\text { Например, заказ желаемой еды через Ин- } \\
\text { тернет; реализация сексуальных потреб- } \\
\text { ностей с помощью порно-сайтов. }\end{array}$ \\
\hline
\end{tabular}

(Плешаков, 2010)

Это многообразие «цифровой жизни» не может не повлиять на восприятие изначально уже виртуального понятия «бренд» современным потребителем и делает его в информационном обществе еще более виртуальным.

По нашему мнению, виртуальный бренд может быть реализован в нескольких видах в зависимости от степени виртуальности среды или компании, в которой и для которой существует: 


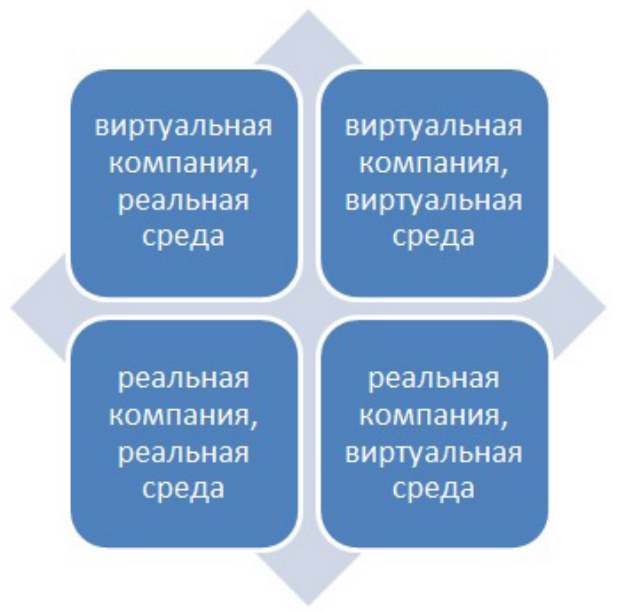

По оси ОХ - уровень виртуальности среды

По оси ОY - уровень виртуальности компании

Рисунок 1. Типы виртуальных брендов.

Рассмотрим способы реализации этой виртуальности в современных условиях:

1. Реальный бренд в виртуальном пространстве. Это одна из самых распространенных моделей существования современных брендов. Найти компанию, имеющую сильный бренд и не представленную в онлайн-среде сегодня почти невозможно. Сама онлайн-среда может быть достаточно многообразна и инструменты интернет-маркетинга позволяют по-разному представлять компанию на рынке. Это может быть:

- бренд существующей компании, представленный через сайт компании;

- брендирование страницы компании в социальных сетях;

- виртуальные туры по магазину, офису для поддержки бренда;

- личный виртуальный бренд известного лица (политика, актера, поп-персоны, консультанта). В последнем случае, для пользователей такого бренда (поклонников), часто не является секретом, что сайт или страницу в социальных сетях ведет не сам персонаж, а специальные сотрудники или даже PR-агентство.

Для продвижения в интернет-брендинге, кроме создания сайтов и страниц в социальных сетях используются: поисковое продвижение, PR-мероприятия, работу с интернет-каталогами и досками объявлений; аналитические и обзорные статьи в интернет-СМИ; баннерную рекламу различных видов; e-mail-маркетинг и т. п. Многообразие инструментов позволяет, в определенной степени, создать у потребителя ощущение повсеместного присутствия бренда и добавить реальности в его восприятии. Особенно в этом преуспевают компании, использующие виртуальные туры для про- 
движения бизнеса. Такая форма коммуникации с потребителем называется VR-опыт (Ежиков, Электр. ресурс) и широко используется для того, чтобы передать пользователю ощущения от использования продукта до того, как он сможет или захочет приобрести этот продукт.

Примером эффективного брендинга в виртуальном пространстве эксперты называют технологию YOUNIVERS (You + Universe), т. е. виртуальный кастомизированный мир. Задача брендов в этой технологии правильно определить потребности виртуального сообщества и привнести в него чтото полезное и ценное, позволяющее участникам получить новые переживания и удовольствие. Интеграция бренда в многопользовательскую онлайн игру захватывает участников и вполне в состоянии принести компании реальный доход: «Second Life ... American Apparel (производитель лёгкой одежды и подобных товаров) открыл свой магазин на частном острове в Second Life. Остров называется 'Lerappa Island', что звучит, как 'apparel' наоборот. Дизайн магазина выполнил гражданин и дизайнер Second Life Эйми Вебер в сотрудничестве со штатным архитектором American Apparel. B магазине продаются родные товары American Apparel, которые можно одеть на своего виртуального персонажа. Прибыль компании за каждый проданный товар составляет около \$1» (Брендинг ..., Электр. ресурс).

2. Бренд виртуальной компании. В условиях развития информационного общества развиваются компании, чей продукт изначально относится к виртуальным, т. е. существует только в виртуальной среде. Типичным примером такой компании можно назвать любой браузер, почтовый сервис или электронную валюту. Уровень виртуализации у всех этих компаний различен и варьируется от почти реальных брендов типа Яндекс, до совершенно виртуальных во всех смыслах крипотовалют типа Bitcoin.

Особым видом такого бренда являются бренды, созданные как виртуальные, но со временем обретшие вполне реальную основу. В виртуальном пространстве компьютерной игры или фильма несуществующий бренд обретает такую потребительскую любовь, что вполне реальные компании развиртуализируют их путем выпуска в реальный оффлайновый мир продукта под этим брендом. Самым ярким примером такого «обратного продакт плейсмента» является сеть ресторанов «Bubba Gump Shrimp Co», появившаяся благодаря фильму «Форрест Гамп». Множество таких брендов появилось благодаря культовому мульт-сериалу «Симпсоны», это и газировка «Buzz Cola», и пиво «Duff», и сеть супермаркетов «Kwik-E-Mart». Поставщиками таких брендов активно выступают компьютерные игры, интернет-меммы, медиавирусы.

Особой формой существования такого бренда может выступать виртуальный персонаж, ведущий вполне реальную жизнь. Возможно, что первым 
Научные труды Московского гуманитарного университета 2018 № 3

примером такого брендирования может быть знаменитая мистификация шотландского поэта Джеймса Макферсона - Оссиан, чьи поэмы не только издаются до сих пор, но и существенно повлияли на историю развития всемирной литературы. Продолжателями тренда здесь могут стать все успешные литературные мистификации: Черубина де Габриак, Эмиль Ажар, Макс Фрай, Борис Акунин, Хольм ван Зайчик и победитель премии «Национальный бестселлер» 2017 г. Фигль-Мигль. Причем важно, что большинство перечисленных нами псевдонимов сослужили добрую службу для продвижения вполне реальных проектов. Литературный критик Анна Наринская отметила в своей статье по поводу вручения премии «Национальный бестселлер»: «Как глупейший псевдоним стал работающей частью проекта - ни этот текст, ни предыдущий подписанный Фиглем-Миглем роман «Щастье» не были бы так завлекательны, не будь мистификация столь очевидной, значься на обложке какая-нибудь похожая на человеческую фамилия» (Наринская, 2011: Электр. ресурс).

Современные блоггеры постепенно осваивают нишу оффлайнового маркетинга и из виртуальных персонажей постепенно превращаются в персонажи-бренды. В таких случаях, крупные бренды могут предложить блоггеру «коллаборацию», т.е. создание партии товара под совместным брендом компании и блоггера. Так происходит развиртуализация виртуального бренда самого блоггера. В 2013 и 2014 годах марка модной одежды Marc O`Polo выпустила коллекцию одежды совместно с известным французским блоггером и иллюстратором Гарансом Доре (Зачем брендам ... , Электр. ресурс). Коллаборация оказалась настолько успешной, что проходила два года подряд. Но пока, чаще компании используют блоггеров как успешный PR-инструмент, не допуская их к процессу создания товаров.

3. Виртуальный бренд виртуальной компании - это особый случай существования виртуального бренда. Здесь следует учитывать, что сама виртуальная среда еще не достаточно сформировалась и бренды внутри такой среды существуют очень локально, а маркетинг сильно таргетирован. Среди виртуальных товаров не так много брендов, а еще меньше брендов широко известных и популярных.

Первая проблема, которая возникает при анализе этого рынка, состоит в том, что необходимо разграничивать понятия «виртуальный товар» и «информационный товар». В работе 2005 года Фэрфилд (J. Fairfield) предложил определять виртуальные товары как товары конкурентные, т.е. использование виртуального товара одним человеком исключает одновременное использование этого же товара другими (За что ... , Электр. ресурс). Также, по мнению Фэрфильда, виртуальные товары устойчивы, т. е. существуют определенный период времени и не исчезают сразу после выключения ком- 
пьютера, и взаимосвязаны, т. е. не изолированы и могут влиять на других пользователей или системы. Информационные товары же могут использоваться одновременно несколькими людьми, неустойчивы и изолированы в процессе использования.

Исследователи отмечают, что на желание приобретать виртуальные товары влияют следующие факторы:

- Функциональные атрибуты;

- Гедонистические атрибуты;

- Социальные атрибуты;

- Индивидуальные различия;

- Связь с внешней культурой.

Все эти характеристики близки и оффлайновым брендам, что роднит виртуальные товары и реальные. Однако, на рынке еще не встречались ситуации, когда известный виртуальный дизайнер делал бы свои брендовые товары, например, для онлайн-игр нескольких производителей. Но существуют другие форматы виртуальных брендов в виртуальном пространстве. Самые распространенные, конечно, это бренды приложений для совершения каких-либо действий в виртуальной среде. Сюда можно отнести все виды социальных сетей, приложения для поиска товаров или сравнения цен на товары, приложения для прослушивания музыки или просмотра фильмов. Некоторые из брендов реализуют стандартную зонтичную стратегию, расширяя спектр предлагаемых приложений (товаров) под единым брендом. Так, социальная сеть может со временем обзавестись собственным мессенджером, онлайн-магазином, хранилищем данных и т. п., причем все перечисленные элементы могут работать как единая система или по отдельности.

Рассматривая проявления виртуальности брендов не трудно заметить, что в зависимости от вида виртуальности, суть бренда не меняется. Он так и остается совокупностью мечтаний, ожиданий и гарантий для потребителя. Однако, меняются инструменты его продвижения, способы фиксации и презентации, окружающая среда. Следовательно, можно сделать вывод, что происходит не виртуализация сущности бренда (он и так виртуален по своей природе), а виртуализация инструментария брендинга, работы с брендом с трансформирующемся информационном обществе.

\section{СПИСОК ЛИТЕРАТУРЫ}

Брендинг в метавселенной [Электронный ресурс] // blog.worldwebstudio.com. URL: http://blog.worldwebstudio.com/?p=94\#more-94 (дата обращения: 20.11.2017). 
Гибсон, У. Neuromancer (Нейромантик) [Электронный ресурс] // URL: http://www.lib.ru/GIBSON/gibso01.txt (дата обращения: 20.11.2017).

Ёжиков, А. Виртуальный «нарратив»: как использовать разные типы опыта в VR-продуктах? [Электронный ресурс] // Forbes. URL: http://www. forbes.ru/tehnologii/344853-virtualnyy-narrativ-kak-ispolzovat-raznye-tipyopyta-v-vr-produktah (дата обращения: 20.11.2017).

За что ценят виртуальные товары? Реферат статьи Вили Ледонвирта [Электронный ресурс] // Obs.Ru. URL: http://www.obs.ru/article/1820/ (дата обращения: 20.11.2017).

Зачем брендам коллаборации с блогерами? [Электронный ресурс] // helloblogger.ru. URL: http://helloblogger.ru/journal/brendy-i-blogery-istoriiuspeha/ (дата обращения: 20.11.2017).

Кирик, Т. А. (2007) Виртуальная реальность и ее онтологические прототипы. Курган.

Леушкин, Р. В. (2014) Виртуальный объект как проблема конструктивного реализма // Фундаментальные исследования. № 6 (ч. 7). С. 1553-1558.

Наринская, А. (2011) Отгадка не имеет значения. О романе, который написал Фигль-Мигль [Электронный ресурс] // Коммерсантъ-Weekend. 01.07. URL: https://www.kommersant.ru/doc/1667470 (дата обращения: 20.11.2017).

Панкрухин, А. П. (2001) Бренды и брендинг // Практический маркетинг. № 4(170). С. 4-5.

Плешаков, В. А. (2010) О социальном воспитании в контексте киберсоциализации человека// Вопросы воспитания. № 4 (5). С. 89-98.

Рузави, Г. И. (2010) Виртуальность // Новая философская энциклопедия / предс. науч.-ред. совета В. С. Стёпин, заместители предс.: А. А. Гусейнов, Г. Ю. Семигин, уч. секр. А. П. Огурцов. М.

Симакина, М. А. (2012) Трансформация качества жизни в условиях перехода к информационному обществу : дисс. ... канд. эк. н. М.

Хэмит, Ф. (1995) Виртуальная реальность (Дайджест книги) [Электронный ресурс] // Возможные миры и виртуальные реальности. M. Bып. I. URL: http://www.0viv.ru/cont/pwvr/1.html (дата обращения: 20.11.2017).

Дата поступления: 30.12.2017 г.

Симакина Марина Анатольевна - кандидат экономических наук, доцент кафедры статистики, маркетинга и бухгалтерского учета Московского гуманитарного университета. Адрес: 111395, Россия, г. Москва, ул. Юности, д. 5 . Тел.: +7 (499) 374-79-52. Эл. адрес: msimakina@mosgu.ru 
Simakina Marina Anatolyevna, Candidate of Economics, Associate Professor, Department of Statistics, Marketing and Accounting, Moscow University for the Humanities. Postal address: 5, Yunosti St., Moscow, Russian Federation, 111395. Tel.: +7 (499) 374-79-52. E-mail: msimakina@mosgu.ru

\section{Для цитирования:}

Симакина М. А. Виртуальный бренд: подходы к определению [Электронный ресурс] // Научные труды Московского гуманитарного университета. 2018. № 3. URL: http://journals.mosgu.ru/trudy/article/view/747 (дата обращения: дд.мм.гг.). DOI: 10.17805/trudy.2018.3.10 